\title{
Optimal international tax coordination and economic integration: a game-theoretic framework
}

Citation for published version (APA):

Owen, R., \& Peters, H. J. M. (2000). Optimal international tax coordination and economic integration: a game-theoretic framework. METEOR, Maastricht University School of Business and Economics. METEOR Research Memorandum No. 005 https://doi.org/10.26481/umamet.2000005

Document status and date:

Published: 01/01/2000

DOI:

10.26481/umamet.2000005

Document Version:

Publisher's PDF, also known as Version of record

\section{Please check the document version of this publication:}

- A submitted manuscript is the version of the article upon submission and before peer-review. There can be important differences between the submitted version and the official published version of record. People interested in the research are advised to contact the author for the final version of the publication, or visit the DOI to the publisher's website.

- The final author version and the galley proof are versions of the publication after peer review.

- The final published version features the final layout of the paper including the volume, issue and page numbers.

Link to publication

\footnotetext{
General rights rights.

- You may freely distribute the URL identifying the publication in the public portal. please follow below link for the End User Agreement:

www.umlib.nl/taverne-license

Take down policy

If you believe that this document breaches copyright please contact us at:

repository@maastrichtuniversity.nl

providing details and we will investigate your claim.
}

Copyright and moral rights for the publications made accessible in the public portal are retained by the authors and/or other copyright owners and it is a condition of accessing publications that users recognise and abide by the legal requirements associated with these

- Users may download and print one copy of any publication from the public portal for the purpose of private study or research.

- You may not further distribute the material or use it for any profit-making activity or commercial gain

If the publication is distributed under the terms of Article $25 \mathrm{fa}$ of the Dutch Copyright Act, indicated by the "Taverne" license above, 


\title{
Optimal International Tax Coordination and Economic Integration: A Game-Theoretic Framework*
}

\author{
Robert F. Owen ${ }^{\dagger} \quad$ Hans Peters ${ }^{\ddagger}$ \\ February, 2000
}

\begin{abstract}
The scope for optimal international coordination of indirect taxes is examined in a macroeconomic game-theoretic framework which encompasses two regionally integrated economies, which have a single goods market. In each country there are tax-financed non-tradeable public goods, while labor is immobile internationally. The analysis of both fixed and flexible wage versions of the model identifies a much wider spectrum of cooperative tax policies than has been previously recognized. In relation to noncooperative Nash equilibria, cooperative Pareto-improving tax changes can entail not only uni-directional increases or decreases in rates, but also asymmetric directional changes. In particular, the constellation of such welfare improving tax changes is shown to depend critically on the countries' relative preferences for private and public goods consumption, savings, as well as demand elasticity values relative to unit elasticity.
\end{abstract}

JEL classification numbers: 400, 423, 320.

Key words: indirect tax coordination, economic integration, Nash equilibrium, social welfare.

\section{Introduction}

Taxation policies have long been one of the great bastions of individual countries' economic autonomy. Yet, in recent years heightened economic integration has generated considerable policy attention to alternative scenarios for tax coordination. Notably, in the European Union significant harmonization of value-added tax rates has already been undertaken. Moreover, the ongoing process of European monetary integration, which entails increased

*The authors are indebted to Hans de Graaff for programming the reported model simulations. Earlier versions of this paper have been presented at annual meetings of the European Economic Association, the North American Economics and Finance Association, and the French Journées Macroéconomiques, as well as at the University of Evry. The comments of participants at these conferences and seminar are gratefully acknowledged.

${ }^{\dagger}$ LEN-C3E Research Centre, Faculty of Economics and Business Administration, University of Nantes, Chemin de la Censive du Tertre, B.P. 52231, 44322 Nantes Cedex 3, France. Telephone numbers: 33-2-40141761 (direct) and 33-2-40141717. Fax number: 33-1-39219096. E-mail address: RobertOwen@compuserve.com

$\ddagger$ Department of Quantitative Economics, University of Maastricht, P.O. Box 616, 6200 MD Maastricht, The Netherlands. Telephone numbers: 31-43-3883288 (direct) and 31-43-3883834/35. Fax number: 31-433884874. E-mail address: h.peters@ke.unimaas.nl 
international price transparency and constraints on national governments' budgets, will undoubtedly generate additional pressures for further tax coordination. Nonetheless, to date, most of the European policy debates have focused on piecemeal international tax reform, relating to achieving uniform indirect tax rates. Such an approach risks overlooking the potential interdependence between the effects of such indirect tax changes and distinctive budgetary and other characteristics of increasingly integrated national economies. Differences across countries in direct tax levels, macroeconomic conditions, the overall composition of governments' tax receipts, the size of public sectors, along with international patterns of consumption, savings, and investment could be crucial for evaluating the welfare implications of international tax changes. To the extent that such factors are not adequately considered, there is the potential for specific policy initiatives generating solutions where welfare actually decreases in one or more participating countries. ${ }^{1}$

Despite policy initiatives calling for coordinated tax changes, there is a relative paucity of analytic models, and associated policy analysis, offering an integrated perspective for defining optimal international policy changes. A central contribution of the present researchwhich is an extension and reformulation of Owen and Peters (1990) - is to offer a gametheoretic framework which identifies, and offers alternative explanations for, a much wider set of cooperative Pareto-improving indirect tax rates, than what has been recognized in the existing literature. The proposed macroeconomic framework considers two regionally integrated economies, which have a single consumption goods market. In each country there is a tax-financed non-tradeable public good, while labor is immobile internationally. The choice of indirect tax rates impacts on social welfare in each country through its effects on demand for the consumption good, private-sector savings, and government expenditures. The analysis of both fixed and flexible wage versions of the model identifies a much wider spectrum of cooperative tax policies than has been previously recognized. In relation to noncooperative Nash equilibria, cooperative Pareto-improving tax changes can entail not only uni-directional increases or decreases in rates, but also asymmetric directional changes. In the fixed wage version, when marginal propensities to save are low and consumption demand in both countries is elastic, reflecting strong social preferences for the public good, optimal tax coordination entails decreased indirect tax rates in both countries. This results from positive international multiplier effects, due to decreased prices in both countries. However, it is also shown that quantitative changes in optimal indirect tax rates depend on a number of other factors, including direct tax rates and whether wages are rigid or flexible.

A noteworthy early contribution ${ }^{2}$ to the literature on international tax coordination is the model formulated by Mintz and Tulkens (1986) and further elaborated by Crombrugghe and Tulkens (1989), which relates to the specific issue of indirect tax coordination. Unlike the findings reported in the present research, a central proposition to emerge from this research is that there do not exist Pareto-improving value-added tax changes between two countries, where both their tax rates are reduced. Yet, the generality of this finding appears to be crucially related to certain restrictive assumptions. In the framework proposed by Mintz and Tulkens, where labour supplies are untaxed, it is postulated that labour migration between two regions in an economic union occurs in response to trade imbalances generated by indi-

\footnotetext{
${ }^{1}$ The proposition that welfare-improving tax reform is predicated on the interdependence between direct and indirect taxes has been clearly recognized in the closed economy taxation literature. See, for example, the discussion in Atkinson and Stiglitz (1980).

${ }^{2}$ Cnossen (1985), which includes contributions by Cnossen and Shoup (1985) and Rose (1985), has offered a perspective on certain analytic and policy issues relating to international tax reform in the European Community in the early 1980s.
} 
rect tax changes. ${ }^{3}$ Furthermore, their assumption that commodity arbitrage entails convex transportation costs implies an associated disincentive effect to such arbitrage, which offsets standard Keynesian multiplier mechanisms associated with eventual price reductions linked to hypothetical tax changes. Yet, other characteristics of their basic approach appear more robust. In particular, the comparison of Nash equilibria associated with a non-cooperative game between governments with outcomes arising from the coordination of indirect taxes, sequential optimization by governments and then consumers, and the inclusion of both a private consumption good and tax-financed public goods in each of the two regions are specifications akin to those proposed in the present research.

An alternative analysis of the welfare effects of commodity tax harmonization has been offered by Keen (1987). In the context of a two-country model with $N$ goods, and given a technical assumption, it is demonstrated that averages of ex ante indirect tax rates constitute feasible welfare improving tax changes. However, there are again a number of restrictive aspects of the analysis. In particular, Keen's central finding is predicated on there being welfare compensating transfers between the countries. Furthermore, the analysis focuses on Pareto-improving indirect tax changes, relative to an arbitrary pair of international taxes, rather than to a Nash-Equilibrium tax combination. In a subsequent paper, Keen (1989) has relaxed the assumption of welfare compensating transfers, but added differential tax rates between imported and domestically produced goods.

The focus in the recent work by Lockwood (1997), Lahiri and Raimondos-Moller (1998), and Lopez-Garcia (1998) is on sets of conditions under which tax harmonization, which is a more specific form of tax coordination, is welfare improving. These papers propose twocountry models with private goods as well as tax-financed public goods. Lockwood (1997) assumes a Ricardian paradigm in which changes in indirect taxes have terms of trade effects that are akin to those arising from tariff changes. Lahiri and Raimondos-Moller (1998) adopt transfers between governments as the mechanism that drives the game. In their setup, since the governments optimize on public good levels only, a Nash equilibrium already constitutes a Pareto optimum, so that it would not leave scope for improvements. Thus, like Keen (1987), they consider arbitrary initial positions. Lopez-Garcia (1998) adopts an approach which is more partial equilibrium in the sense that the representative consumers fulfill the role of the governments in our model, but these do not optimize on the public good levels. Nonetheless, the findings of these more recent papers are to a certain degree consistent with our own, since they suggest that Pareto improving indirect tax changes are potentially ambiguous and may depend on several factors. Our model has a more general equilibrium character, but under the proposed assumptions precise conclusions still turn out to be possible.

The organization of the rest of this paper is as follows. In Section 2 the basic Keynesian model of the two economically integrated countries is set forth. Section 3 initially offers a detailed characterization of the non-cooperative governmental strategies associated with a Nash equilibrium in each country's optimal indirect tax rate. Based on this analysis, the scope for, and nature of, cooperative Pareto-improving tax changes for the two countries is

\footnotetext{
${ }^{3}$ In their formulation transportation costs are the essential mechanism by which gross prices are equilibrated between the two regions. This feature, that price adjustments must be accommodated by labour migration, seems rather tenuous, since the transaction costs and contractual relations in goods and labour markets are arguably quite different. Indeed, in the case of the European Union, the weight of empirical evidence suggests a much lower degree of mobility for labour, than for goods. In fact, in the Mintz and Tulkens paradigm interregional labour and goods movements are complimentary, whereas many models of international trade assume substitutability.
} 
examined, in relation to the Nash equilibrium taxes. Section 4 presents a simulation that illustrates the foregoing results. In Section 5 a variation of the model is investigated, namely the case of flexible wages. In a concluding section, the basic propositions of this paper are briefly summarized, and directions for continued research are identified.

\section{The Basic Model}

It is assumed that there are two countries, designated as domestic and foreign, which are symmetric in their general structure. An asterisk is used to distinguish notation relating to the foreign country. The countries form a partially-integrated economic region in the sense that there are no trade costs for the single tradeable consumption good, $x$. Yet, in each country there are government supplied national public goods, $g$ and $g^{*}$, which can only be consumed at home. Furthermore, labour is immobile between the two countries.

The proposed comparative static analysis will focus on the welfare implications of changing indirect tax changes during a single period. The utility of the representative consumers in each country depends on their consumption of the single homogeneous (traded) good, and the holdings of the home currency, either $m$ or $m^{*}$. Hence, the domestic and foreign consumers maximize utility subject to the corresponding budget constraints:

$$
\begin{aligned}
q x+m_{1} & =y+m_{0} \\
q^{*} x^{*}+m_{1}^{*} & =y^{*}+m_{0}^{*}
\end{aligned}
$$

The symbols $q$ and $q^{*}$ designate consumer prices in each country, while $m_{0}$ and $m_{1}$ are, respectively, beginning and end-of-period holdings of money balances (in the case of domestic consumers), and $y$ and $y^{*}$ are accrued financial resources within the period, which will be subsequently specified. An individual's consumption of the single traded good and endof-period holdings of money balance (hence, savings) are chosen optimally, depending on wage or other earnings, beginning-of-period money balances, as well as a set of exogenous tax, price and other parameters. This will be expressed by consumer demand functions specified below. From the perspective of such a representative consumer, the amount of the public good is exogenously given. However, each government optimally determines $g$ and $g^{*}$ as a result of their maximization of anticipated social welfare prior to individuals' private consumption decisions during the designated period.

In each country there is a fixed number of consumers, either $N$ or $N^{*}$. The model initially adopts a Keynesian style paradigm that nominal wages in each country, $w$ and $w^{*}$, are rigid during the single time period under consideration. Given endogenously determined, aggregate demand for the traded and public goods, there are associated labour demands in each country. The number of employed consumers, in respectively the domestic and foreign country, are indicated by $\ell$ and $\ell^{*}$, so that the unemployed equal $N-\ell$ and $N^{*}-\ell^{*}$. In Section 5 , an alternative flexible-wage, full-employment version of the model is considered.

In the rigid nominal wage version of the model, the overall net financial resources of representative consumers in each country, depend on whether they are employed or not. A superscript, $u$, is used to distinguish notation referring to unemployed consumers. In

\footnotetext{
${ }^{4} \mathrm{~A}$ single homogeous good is assumed for methodological simplicity. In contrast to most earlier research, the present analysis postulates a more general equilibrium framework for examining issues of international tax coordination. Such an approach entails tradeoffs in the complexity and non-linearities of proposed models. Incorporating additional private consumption goods would add cross-price effects, which could substantially complicate the analysis, without affecting certain of the fundamental propositions formulated here.
} 
addition to holding beginning-of-period money balances, consumers either earn income or receive net unemployment compensation from their government, $s$ or $s^{*}{ }^{5}$ The latter are assumed to be strictly smaller than potential wage earnings. Accordingly, if it is assumed that each employed individual works for one unit of time, and exogenous levels of direct taxes are given by $T$ and $T^{*}$, the following inequalities apply:

$$
(1-T) w>s, \quad\left(1-T^{*}\right) w^{*}>s^{*} .
$$

A central concern of the subsequent analysis is on the role of indirect tax rates, $t$ and $t^{*}$, as governmental decision variables in a strategic game played between the two countries. ${ }^{6}$ In particular, the tax rates and welfare effects resulting from non-cooperative Nash behavior, will be compared with solutions entailing international cooperation in the determination of indirect tax rates. Since such government tax policies are formulated prior to the time period under consideration, these indirect tax rates are also taken to be exogenous from the standpoint of individual consumers. Producer prices for the private consumption good are assumed fixed and, for convenience, set equal to 1 , consumer prices in the domestic and foreign countries are given by, respectively, $q=1+t$ and $q^{*}=1+t^{*}$.

In light of the foregoing assumptions, the generic form for the demand functions of employed or unemployed consumers in the two countries can be represented (for the domestic country) as $x(q, Y)$, where $Y$ denotes the total monetary resources of a given consumer. In addition to beginning-of-period money balance, these resources include either earned income or government unemployment compensation. Standard assumptions regarding the demand functions apply. In particular, it is assumed that these functions are sufficiently differentiable, that private consumption is a normal good, and there are negative own price effects. Accordingly, the following conditions regarding partial derivatives (denoted by subscripts) hold:

$$
x_{q}<0, x_{Y}>0, x_{q^{*}}^{*}<0, x_{Y^{*}}^{*}>0 .
$$

By way of summary, the following demand functions for the employed and unemployed consumers in both countries can be identified:

$$
\begin{array}{ll}
x=x\left(1+t,(1-T) w+m_{0}\right) & \text { for the employed } \\
x^{u}=x\left(1+t, s+m_{0}^{u}\right) & \text { for the unemployed } \\
x^{*}=x^{*}\left(1+t^{*},\left(1-T^{*}\right) w^{*}+m_{0}^{*}\right) & \text { for the employed } \\
x^{u *}=x^{*}\left(1+t^{*}, s^{*}+m_{0}^{u *}\right) & \text { for the unemployed }
\end{array}
$$

A standard macroeconomic assumption is made that, ceteris paribus, employed consumers have a higher marginal propensity to save, in a given period, than the unemployed. Formally, the following inequalities are assumed:

$$
m_{1}-m_{0}>m_{1}^{u}-m_{0}^{u} \text { and } m_{1}^{*}-m_{0}^{*}>m_{1}^{u *}-m_{0}^{u *}
$$

\footnotetext{
${ }^{5}$ The fixed 'social welfare' payments are not subject to income tax.

${ }^{6}$ The analysis of this paper principally focuses on the optimal determination of indirect tax rates and the rationale for their international coordination. It is apparent that the proposed framework could be extended to consider a more general international setting of optimal public finance decisions, where the strategic international interdependence between an array of national public sector revenue and expenditure decision variables would be examined. Certain suggestions regarding such an extension of the analysis are offered in the concluding section.
} 
In light of the consumers' budget constraints in (1), a straightforward calculation reveals that the foregoing inequalities are equivalent to:

$$
\frac{(1-T) w-s}{1+t}>x-x^{u} \text { and } \frac{\left(1-T^{*}\right) w^{*}-s^{*}}{1+t^{*}}>x^{*}-x^{u *} .
$$

Hence, the additional net income from becoming employed exceeds the increased consumption of the private good.

Further, assumptions are made that the unemployed consumers actually dissave over the single period, and that the beginning-of-period money balances of the unemployed do not exceed those of employed consumers; formally,

$$
m_{1}^{u}<m_{0}^{u} \text { and } m_{1}^{u *}<m_{0}^{u *}
$$

and

$$
m_{0}^{u} \leq m_{0} \text { and } m_{0}^{u *} \leq m_{0}^{*} .
$$

Inequalities (6) and (7) guarantee that labor supply will be positive, while (8) is a necessary condition for determining certain qualitative results. ${ }^{7}$

The production side of the economy is characterized by several simplifying features. These specifications are motivated by the postulated Keynesian paradigm, in which aggregate demand plays a crucial role, and since they facilitate tractable analytic solutions. More specifically, constant returns to scale, along with zero profits, are assumed, while labour is the only factor of production. In addition, it is hypothesized that the processes for producing the public and private goods in each country are identical, even though these goods have different end-uses. ${ }^{8}$ The overall production functions in the two countries can be represented as follows:

$$
Z=\lambda \ell, Z^{*}=\lambda^{*} \ell^{*}
$$

The symbols, $Z$ and $Z^{*}$, denote the total production of both the public and private goods in each country, while $\lambda$ and $\lambda^{*}$ capture the prevailing marginal productivities of labour in each country. Under the hypotheses of zero profits, these technological coefficients, which are assumed to be constant, and equal to the nominal wages in each country (hence, $\lambda=w$ and $\left.\lambda^{*}=w^{*}\right)$. They thereby reflect the overall standards of living of employed consumers.

In light of earlier specifications, the basic market clearing condition for the economically integrated market for the single tradeable good is given by:

$$
g+\ell x+(N-\ell) x^{u}+g^{*}+\ell^{*} x^{*}+\left(N^{*}-\ell^{*}\right) x^{u *}=\lambda \ell+\lambda^{*} \ell^{*} .
$$

This equation reflects the combined assumptions of a Keynesian scenario of rigid nominal wages, a single tradeable consumption good, and the one-to-one transformation process between the private and public goods. With short-run nominal wage rigidity, it is necessary to stipulate a rationing mechanism which allocates global aggregate demand between producers in the two countries. A linear rationing rule for allocating labour demand between the domestic and foreign markets, is postulated (again for simplicity):

$$
\ell^{*}=\alpha \ell .
$$

\footnotetext{
${ }^{7}$ Specifically, it is used in the derivation of inequality (28).

${ }^{8}$ At the price of heightened complexity, a useful extension of the analysis could entail distinct production processes for public and private goods.
} 
The positive coefficient, $\alpha$, is assumed to be exogenous.

The exchange rate is taken to be fixed and arbitrarily set equal to one. With such a specification there will be potential excess supplies or demands for the two countries' moneys depending on whether they produce more than they consume of the tradeable private good. In order for the exchange rate to be constant, accommodating monetary policies must also be assumed, such that at least one central bank uses its reserves to eliminate the excess demand and supplies for the two countries currencies.

The foregoing formulation of the basic model, along with an assumption of no-debt financing, yields the following balanced-budget constraints for the two governments:

$$
\begin{aligned}
& g=\ell(t x+T w)+(N-\ell)\left(t x^{u}-s\right) \\
& g^{*}=\ell^{*}\left(t^{*} x^{*}+T^{*} w^{*}\right)+\left(N^{*}-\ell^{*}\right)\left(t^{*} x^{u *}-s^{*}\right) .
\end{aligned}
$$

Government expenditures (other than unemployment compensation) equal the sum of direct and indirect tax payments by workers, while the final term in each equation reflects the net fiscal impact of unemployment.

Both governments are understood to maximize the following social welfare functions, by optimally choosing their indirect tax rates, $t$ and $t^{*}$,

$$
u=u(X, g, M) \text { and } u^{*}=u^{*}\left(X^{*}, g^{*}, M^{*}\right)
$$

where

$$
\begin{array}{ll}
X=\ell x+(N-\ell) x^{u}, & M=\ell m_{1}+(N-\ell) m_{1}^{u} \\
X^{*}=\ell^{*} x^{*}+\left(N^{*}-\ell^{*}\right) x^{u *}, & M^{*}=\ell^{*} m_{1}^{*}+\left(N^{*}-\ell^{*}\right) m_{1}^{u *} .
\end{array}
$$

These welfare functions, which reflect the objectives of maximizing private and public good consumption and end-of-period money holdings are assumed to be increasing in all these objectives:

$$
u_{X}, u_{g}, u_{M}, u_{X^{*}}^{*}, u_{g^{*}}^{*}, u_{M^{*}}^{*}>0
$$

In the next section two alternative outcomes, under Nash assumptions and with tax coordination, will be characterized and compared.

\section{Non-cooperative Tax Strategies Versus Tax Coordi- nation}

\subsection{A General Perspective}

The analysis of this section juxtaposes the determination of optimal indirect tax levels, under the assumption of non-cooperative, Nash equilibrium behavior by the two governments, with those which arise from international cooperation when setting indirect tax rates. A key, associated policy question is the evaluation of the extent to which optimal tax coordination entails commodity tax harmonization (including the special case of uniform rates), as currently advocated in the context of certain policy debates within the European Union. By contrast, it is conceivable that cooperative international tax solutions yield either quite divergent changes in the constellations of international tax rate changes, or uniformly higher or lower indirect tax levels.

In the initial Nash equilibrium setting, an international tax game is postulated, in which the governments are players who optimally determine their commodity taxes on the strategic 
spaces of values for $t$ and $t^{*} .{ }^{9}$ Accordingly, the associated, reduced form solutions for the social welfare functions can be viewed as payoff functions. These reduced forms are obtained by expressing the social welfare functions as functions of the decision variables, $t$ and $t^{*}$, which, in turn, depend on the direct tax rates, unemployment payments, and other parameter values in the two countries. At an interior Nash equilibrium the indirect tax rates $\left(\tilde{t}, \tilde{t}^{*}\right)$ satisfy:

$$
\frac{d u}{d t}\left(\tilde{t}, \tilde{t}^{*}\right)=\frac{d u^{*}}{d t^{*}}\left(\tilde{t}, \tilde{t}^{*}\right)=0 .
$$

The analysis of tax coordination is based on a local comparative static analysis relative to the initial Nash equilibrium satisfying (15). ${ }^{10}$ Consequently, the characterization of Pareto improving cooperative tax changes is based on an investigation of how the payoff functions for the two countries react to small deviations from the Nash equilibrium taxes. The fundamental result to emerge is that there is a wide configuration of feasible cooperative tax changes that lead to Pareto improvement of social welfare in both countries. Several different scenarios are identified. Indirect taxes can either simultaneously increase or decrease in both countries, or there can be asymmetric directional tax changes, where rates increase in a given country, while decreasing in the other one. The existence of such a wide spectrum of Pareto improving tax changes is shown to depend on the relative preference in each of the two countries for the private and public goods and the end-of-period money balances. Several different scenarios correspond to different sets of elasticity conditions in the two countries. In particular, they are determined by whether demand for the private consumption good is elastic or inelastic.

\subsection{The Specific Analysis and Results}

An essential preliminary step involves the determination of the expressions and signs for the total derivatives of the endogenous demand for labour, $\ell$ and $\ell^{*}$, with respect to $t$ and $t^{*}$. In light of the labour rationing rule, specified in equation (10), it suffices to determine the results for the domestic labour demand. Substitution of the budget constraints for the two countries, given in (11), and the rationing rule into the basic market clearing equation, given by (9), yields the following:

$$
-\ell S+N\left(t x^{u}-s\right)+N x^{u}+N^{*}\left(t^{*} x^{u *}-s^{*}\right)+N^{*} x^{u *}=0,
$$

where the expression denoted by $S$ will play an important role in the subsequent derivations, and is given by:

$$
S:=[(1-T) w-s]-(1+t)\left(x-x^{u}\right)+\alpha\left\{\left[\left(1-T^{*}\right) w^{*}-s^{*}\right]-\left(1+t^{*}\right)\left(x^{*}-x^{u *}\right)\right\} .
$$

The quantity $S$ can be interpreted as the additional savings resulting from the hiring of an additional worker in the domestic country and $\alpha$ extra workers in the foreign country. The first term in $S$ constitutes the additional per capita income resulting from becoming

\footnotetext{
${ }^{9}$ Alternatively, the public expenditure levels could be viewed as strategic variables. Wildasin (1988) formulates a model where the maximization of social welfare with respect to taxes or public expenditures can yield different Nash equilibria.

${ }^{10}$ The primary focus here is not on the existence or uniqueness of an interior Nash equilibrium. Our results hold conditional on the assumption of an interior Nash equilibrium. The simulation in Section 4 shows that these results are nonvoid.
} 
employed, whereas the terms $\left(x-x^{u}\right)$ and $t\left(x-x^{u}\right)$ are, respectively, the associated increase in private consumption and government revenues (hence, expenditure). In light of the inequalities expressed in (6), it follows that the value of $S$ is positive.

Totally differentiating (16) with respect to $t$ results in:

$$
-\frac{d \ell}{d t} S-\ell \frac{d S}{d t}+N\left(x^{u}+t x_{q}^{u}\right)+N x_{q}^{u}=0 .
$$

By totally differentiating the expression for $S$ with respect to $t$ one obtains:

$$
\frac{d S}{d t}=-\left(x-x^{u}\right)-(1+t)\left(x_{q}-x_{q}^{u}\right)
$$

Combining (18) and (19) yields the following series of equations, which are finally rewritten to include terms which contain the price elasticities for $x$ and $x^{u}$, denoted, respectively, by $\varepsilon(x)$ and $\varepsilon\left(x^{u}\right)$ :

$$
\begin{aligned}
\frac{d \ell}{d t} S & =\ell\left[x+(t+1) x_{q}\right]+(N-\ell)\left[x^{u}+(t+1) x_{q}^{u}\right] \\
& =\ell \frac{d}{d q}(q x)+(N-\ell) \frac{d}{d q}\left(q x^{u}\right) \\
& =\ell x(1+\varepsilon(x))+(N-\ell) x^{u}\left(1+\varepsilon\left(x^{u}\right)\right) .
\end{aligned}
$$

The analysis that follows highlights the importance of the following two expressions, defined as $E$ and $E^{*}$, whose signs are critically influenced by the values of the price elasticities of demand:

$$
\begin{aligned}
E & :=\ell x(1+\varepsilon(x))+(N-\ell) x^{u}\left(1+\varepsilon\left(x^{u}\right)\right) \\
E^{*} & :=\ell^{*} x^{*}\left(1+\varepsilon\left(x^{*}\right)\right)+\left(N^{*}-\ell^{*}\right) x^{u *}\left(1+\varepsilon\left(x^{u *}\right)\right) .
\end{aligned}
$$

Combining (20) and (21) yields that the impact on the domestic country's labour demand of a change in its own indirect tax rate is given by:

$$
\frac{d \ell}{d t}=\frac{E}{S} .
$$

Since $S$ is positive, the sign of $d \ell / d t$ is equal to the sign of $E$ and thus depends critically on the demand elasticities for employed and unemployed consumers in the domestic country. A sufficient condition for a tax increase to actually stimulate labour demand is that the values of $\varepsilon(x)$ and $\varepsilon\left(x^{u}\right)$ both be greater than -1, i.e., that demand be relatively inelastic. The intuition is that an increase in $t$ generates higher government income and associated expenditure, which offsets a relatively small decrease in private sector consumption.

Analogously, by totally differentiating (16) and (17) with respect to the foreign commodity $\operatorname{tax} t^{*}$, and combining results, one has:

$$
\begin{aligned}
\frac{d \ell}{d t^{*}} S & =\ell^{*} \frac{d}{d q^{*}}\left(q^{*} x^{*}\right)+\left(N^{*}-\ell^{*}\right) \frac{d}{d q^{*}}\left(q^{*} x^{u *}\right) \\
& =\ell^{*} x^{*}\left(1+\varepsilon\left(x^{*}\right)\right)+\left(N^{*}-\ell^{*}\right) x^{u *}\left(1+\varepsilon\left(x^{u *}\right)\right) .
\end{aligned}
$$

This yields the following expression for the impact of a change in the foreign indirect tax rate on domestic labour demand:

$$
\frac{d \ell}{d t^{*}}=\frac{E^{*}}{S}
$$


From the foregoing arguments, it is readily apparent that the sign of (24) depends on the foreign country's demand elasticities for employed and unemployed consumers.

In order to assess the impact of a change in its own indirect tax rate on the domestic country's social welfare, under the Nash equilibrium assumption of $t^{*}$ being given, the following, total derivative of the social welfare function $u$ with repect to $t$ needs to be evaluated:

$$
\frac{d u}{d t}=u_{X} \frac{d X}{d t}+u_{g} \frac{d g}{d t}+u_{M} \frac{d M}{d t}
$$

Substitution of the expressions in (13) for total consumption of the private good and the total money holdings, along with that for the government budget constraint in (11), results after some algebraic manipulations in:

$$
d u / d t=(d \ell / d t) A+\left(u_{g}-u_{M}\right) E+\left(u_{X}-u_{g}\right)\left[\ell x_{q}+(N-\ell) x_{q}^{u}\right]
$$

where

$$
A:=\left[u_{X}\left(x-x^{u}\right)+u_{g} t\left(x-x^{u}\right)+u_{g}(T w+s)+u_{M}\left(m_{1}-m_{1}^{u}\right)\right] .
$$

The first term in $(26),(d \ell / d t) A$, represents the impact on social welfare of a change in the indirect tax through the resulting change in employment. This impact is caused by changes in consumption and related indirect (consumption) tax revenues, in direct (income) tax revenues and unemployment compensation payments, and in end-of-period money balances. All these changes are summarized in the expression $A$ in (27). Under the assumptions of the basic model we have:

$$
A>0
$$

The second expression in (26) reflects the induced effect on government expenditures and total end-of-period money holdings, and, hence, social welfare, of changes in the private good consumption of both employed and unemployed consumers, under the premise that employment levels are unchanged. The latter effect is expressed by the two price elasicity values, $\varepsilon(x)$ and $\varepsilon\left(x^{u}\right)$, that are the basic constituents of the expression for $E$. When both demands are inelastic $(E>0)$, for example, there is a minimal erosion of the tax base associated with an increase in the domestic tax rate. Consequently, overall tax revenues increase, thereby generating increased government expenditures, but decreased total endof-period money holdings. The overall effect on social welfare will depend on the relation between $u_{g}$ and $u_{M}$. The opposite scenario applies for the case where the two demand elasticities are elastic $(E<0)$. Despite a higher domestic tax rate, there is a sharp decrease in consumer demand which results in a loss of overall tax revenue. Thus, it is apparent from equation (26) that the values of the domestic demand elasticities have the potential to determine the directional impact of a change in the tax rate, $t$, on domestic social welfare. This insight will be important for the results to be established.

The third expression in (26) comprises two different factors. The latter of these is negative, and reflects the changes (decrease) in consumer demand due to a tax-induced price change (increase). The former term reveals that the impact of these demand changes on social welfare can be either positive or negative. A negative change in demand for the private good has a negative effect on social welfare through the private consumption objective of the government expressed by the factor $+u_{X}$. However, in light of the basic market clearing equation (9), under the premise that employment, $\ell$, and thus total production is kept at the same level, a negative change in demand for the private good must entail a positive change in supply of the public good. This substitution effect is expressed by the factor $-u_{g}$. Hence, 
whether the overall effect of the final expression is negative or positive depends critically on the relative importance of the marginal contributions to social welfare of the government good $g$ and the private sector $X$. When $u_{X}>u_{g}\left(u_{X}<u_{g}\right)$, the sign of this final expression is negative (positive).

To summarize, the analysis of the expression contained in (26), which corresponds to the impact of changes in the domestic tax rate, $t$, on domestic social welfare reveals potentially offsetting influences, leading to an inherent ambiguity in the sign of $d u / d t$. Among other factors, the general indeterminacy of this sign depends, ceteris paribus, on the relative importance of the value of increased consumption associated with becoming employed. On the other hand, other terms in (26) depend on the values of demand elasticities, for the employed and the unemployed consumers, relative to the point of unity elasticity, and on the relative marginal effects on social welfare of changes in government and private good consumption, and end-of-period money holdings.

The following proposition applies for the scenario of an initial interior Nash equilibrium. It identifies the signs of the derivatives of $\ell$ and $\ell^{*}$ with respect to $t$ and $t^{*}$ or, alternatively, of the elasticity expressions $E$ and $E^{*}$, on the relative preferences of the two governments.

PROPOSITION 1 Let $\left(\tilde{t}, \tilde{t}^{*}\right)$ be an interior Nash equilibrium. Then

(i) If $u_{g}>u_{M}$, then $d \ell / d t$ (or $E$ ) and $u_{X}-u_{g}$ have the same sign (positive, negative, or zero).

(ii) If $u_{g^{*}}^{*}>u_{M^{*}}^{*}$, then $d \ell^{*} / d t^{*}$ (or $E^{*}$ ) and $u_{X^{*}}^{*}-u_{g^{*}}^{*}$ have the same sign (positive, negative, or zero).

Here, all derivatives are evaluated at the Nash equilibrium $\left(\tilde{t}, \tilde{t}^{*}\right)$.

Proof Because $\left(\tilde{t}, \tilde{t}^{*}\right)$ is an interior Nash equilibrium, we have

$$
\frac{d u}{d t}\left(\tilde{t}, \tilde{t}^{*}\right)=0
$$

The claim in (i) follows by noting that the coefficient of $d \ell / d t$ in (26) is positive, the coefficient of $u_{X}-u_{g}$ is negative, and $E$ has the same sign as $d \ell / d t$ by equation (22) and the fact that $S>0$. Part (ii) follows similarly.

Observe that, if $u_{g}<u_{M}$ or $u_{g^{*}}^{*}<u_{M^{*}}^{*}$ in Proposition 1, then the relations between the signs of the expressions in (i) and (ii) of the proposition cannot be unambiguously determined from (26) or the analogous expression for the foreign country. This is the case if, at the equilibrium, marginal social welfare for end-of-period money holdings is large relative to that for government expenditures. In the opposite case, however, the signs are unambiguous. A consequence of Proposition 1 is that employment is increasing (decreasing) with the commodity tax if, and only if, the marginal social welfare for the private good, $u_{X}$, is larger (smaller) than the marginal social welfare for the public good $u_{g}$. The intuition for this at first sight somewhat counterintuitive appearing result is as follows. Suppose, for instance, that demand is relatively inelastic. Then an increase in indirect taxes would have a positive effect on social welfare through increased indirect tax revenues and increased public spenditure (and therefore increased direct tax revenues), given that the marginal social welfare for end-of-period money balances is relatively low compared to that of public spenditure, as in the condition of the proposition. The assumption of a Nash equilibrium position, however, 
implies that social welfare is already at a maximum and therefore the induced positive effect of an increase in the indirect tax should be offset by a sufficiently strong negative effect resulting from the small (in view of price inelasticity) decrease in demand. This effect can only be sufficiently strong if there is a relatively strong marginal social welfare for private consumption as compared to government expenditure.

The next proposition concerns the effects of changes in the commodity tax on social welfare in the other country.

PROPOSITION 2 Let $\left(\tilde{t}, \tilde{t}^{*}\right)$ be an interior Nash equilibrium. Then

(i) If $u_{g^{*}}^{*}>u_{M^{*}}^{*}$, then $d u / d t^{*}$ and $u_{X^{*}}^{*}-u_{g^{*}}^{*}$ have the same sign (positive, negative or zero).

(ii) If $u_{g}>u_{M}$, then $d u^{*} / d t$ and $u_{X}-u_{g}$ have the same sign (positive, negative or zero).

All derivatives are evaluated at the Nash equilibrium $\left(\tilde{t}, \tilde{t}^{*}\right)$.

Proof We only prove part (i), the other part is established in an analogous fashion. In light of (11) and (13) we obtain

$$
\begin{aligned}
d u / d t^{*} & =d \ell / d t^{*}\left[\left(u_{X}+t u_{g}\right)\left(x-x^{u}\right)+u_{g}(T w+s)+u_{M}\left(m_{1}-m_{1}^{u}\right)\right] \\
& =d \ell / d t^{*} A .
\end{aligned}
$$

By (28) it follows that the sign of $d u / d t^{*}$ is equal to the sign of $d \ell / d t^{*}$. By (10) the sign of the latter is equal to the sign of $d t^{*} / d t^{*}$. Claim (i) now follows from part (ii) of Proposition 1 .

As in Proposition 1, also in this proposition unambiguous conclusions cannot be drawn if the marginal social welfare for money holdings is larger than for government expenditure.

In order to develop an intuition for Proposition 2, suppose we have an interior Nash equilibrium $\left(\tilde{t}, \tilde{t}^{*}\right)$. Assume, for instance, that $u_{X}>u_{g}$ and $u_{X^{*}}^{*}<u_{g^{*}}^{*}$, and that $u_{g^{*}}^{*}>u_{M^{*}}^{*}$ and $u_{g}>u_{M}$. Then, by Proposition $2, d u^{*} / d t>0$ and $d u / d t^{*}<0$, where the derivatives are evaluated at this Nash equilibrium. Note that, for small changes in the commodity taxes, these effects are of first order, whereas the own effects (of a change in $t$ on $u$ and a change in $t^{*}$ on $u^{*}$ ) are of only second order because

$$
\frac{d u}{d t}\left(\tilde{t}, \tilde{t}^{*}\right)=\frac{d u^{*}}{d t^{*}}\left(\tilde{t}, \tilde{t}^{*}\right)=0 .
$$

Hence, given the assumptions on the relative magnitudes of the marginal social welfare for end-of-period money balances and government expenditure, the effects described in Proposition 2 imply the necessary conditions for a local Pareto improvement relative to the initial position of an interior Nash equilibrium. These findings are summarized in the following theorem, which is the main result of this section.

THEOREM 1 Suppose, at an interior Nash equilibrium, in both countries marginal social welfare for government expenditure is larger than for end-of-period money holdings. Necessary conditions for a local Pareto improvement relative to this equilibrium are the following:

(a) If in both countries the marginal social welfare of private consumption $\left(u_{X}\right.$ and $\left.u_{X^{*}}^{*}\right)$ is larger than that of public consumption $\left(u_{g}\right.$ and $\left.u_{g^{*}}^{*}\right)$, then both commodity taxes should be increased. 
(b) If in the domestic country the marginal social welfare of private consumption $\left(u_{X}\right)$ is larger than that of public consumption $\left(u_{g}\right)$, and in the foreign country it is the other way around, then the domestic commodity tax should be increased and the foreign commodity tax should be decreased.

(c) If in the domestic country the marginal social welfare of private consumption $\left(u_{X}\right)$ is smaller than that of public consumption $\left(u_{g}\right)$, but in the foreign country it is the other way around, then the domestic commodity tax should be decreased and the foreign commodity tax should be decreased.

(d) If in both countries the marginal social welfare of private consumption ( $u_{X}$ and $u_{X^{*}}^{*}$ ) is smaller than that of public consumption $\left(u_{g}\right.$ and $\left.u_{g^{*}}^{*}\right)$, then both commodity taxes should be decreased.

Moreover, in each of the foregoing cases a Pareto improving pair of tax changes exists.

Since at a Nash equilibrium both countries are already at a social optimum, indirect tax changes cannot but influence foreign social welfare, without improving a country's own social welfare. Note that, in all four regimes in Theorem 1, a social welfare improvement in a given country entails a particularly stringent form of tax coordination since it necessitates a change in the other country's tax rate. ${ }^{11}$ Also observe that, in all these regimes, the local Pareto improvement is obtained by an unambiguous increase in total employment: $\ell$ (as well as $\ell^{*}$ ) increase in all cases.

The existence of a specific regime is directly related to the values of the price elasticities in both countries. For instance, consider the regime where $u_{X}>u_{g}$ and $u_{X^{*}}^{*}<u_{g^{*}}^{*}$ (and where in both countries marginal social welfare for government expenditure is larger than for end-of-period money holdings). For this regime to occur, by Proposition 1 necessary and sufficient conditions are

$$
E>0 \text { and } E^{*}<0 \text {. }
$$

Accordingly, the domestic country's demand is relatively price-inelastic, while in the foreign country it is relatively price-elastic, at the initial Nash equilibrium. Considerations of this type are summarized in the following corollary.

COROLLARY 1 Suppose, at an interior Nash equilibrium, in both countries marginal social welfare for government expenditure is larger than for end-of-period money holdings. Necessary conditions for a local Pareto improvement relative to this equilibrium are the following:

(a) If demands in both countries are relatively price-inelastic $\left(E, E^{*}>0\right)$, then both commodity taxes should be increased.

(b) If demand in the domestic country is relatively price-inelastic $(E>0)$ and in the foreign country it is relatively price-elastic $\left(E^{*}<0\right)$, then the domestic commodity tax should be increased and the foreign commodity tax should be decreased.

(c) If demand in the domestic country is relatively price-elastic $(E<0)$ and in the foreign country it is relatively price-inelastic $\left(E^{*}>0\right)$, then the domestic commodity tax should be decreased and the foreign commodity tax should be increased.

\footnotetext{
${ }^{11}$ This is a common phenomenon in non-cooperative games.
} 
(d) If demands in both countries are relatively price-elastic $\left(E, E^{*}<0\right)$, then both commodity taxes should be decreased.

Moreover, in each of the foregoing cases a Pareto improving pair of tax changes exists.

Thus, Corollary 1 identifies the existence of four scenarios (with the exception of zero values). In each of these scenarios, an increase in a given country's social welfare is inherently associated with a change in the other country's commodity tax rate.

\section{A Simulation}

The basic propositions of Theorem 1 are simulated in this section on the basis of a numerical example which assumes that both the demand and social welfare functions are linear. In particular, it will be shown how the set of Pareto-improving tax levels depends crucially on the marginal social welfare associated with private good consumption, public good supply and consumers' end-of-period money holdings. The linear demand functions functions are specified as follows:

$$
\begin{aligned}
x & =a-b(1+t)+c\left((1-T) w+m_{0}\right) \\
x^{u} & =a-b(1+t)+c\left(s+m_{0}^{u}\right) \\
x^{*} & =a^{*}-b^{*}\left(1+t^{*}\right)+c^{*}\left(\left(1-T^{*}\right) w^{*}+m_{0}^{*}\right) \\
x^{u *} & =a^{*}-b^{*}\left(1+t^{*}\right)+c^{*}\left(s^{*}+m_{0}^{u *}\right) .
\end{aligned}
$$

The reported simulations assume a set of identical parameters values for the two countries, which fulfill the basic model conditions (specifically, 2,3,5,7,8, and 14). The specific set of parameter values are provided as a note to Figure 1.

The social welfare functions are given by:

$$
\begin{aligned}
u & =\theta_{1} X+\theta_{2} g+\theta_{3} M \\
u^{*} & =\theta_{1}^{*} X^{*}+\theta_{2}^{*} g^{*}+\theta_{3}^{*} M^{*} .
\end{aligned}
$$

Note that the coefficients in these equations, $\theta_{1}, \theta_{2}, \theta_{3}$, and $\theta_{1}^{*}, \theta_{2}^{*}, \theta_{3}^{*}$, correspond to the marginal social welfare of, repectively, private consumption, public good supply, and end-ofperiod money holdings in the two countries.

In order to illustrate Theorem 1 it is assumed that all the $\theta$-coefficients are positive (condition (14)) and that the values for $\theta_{2}$ are larger than for $\theta_{3}$ in each country. Accordingly, the values of the latter parameters are arbitrarily set equal to 1 , while the four different scenarios illustrated in Figure 1 correspond to different combinations of $\theta_{1}, \theta_{1}^{*}, \theta_{2}$, and $\theta_{2}^{*}$, for values which are greater than 1 . As shown in Figure 1, four different scenarios for Pareto-improving welfare changes are identified for both symmetric and asymmetric tax combinations in the two countries. Each of these cases reflects the corresponding parts of Theorem 1 and Corollary 1. In each diagram an initial pair of indirect tax rates, constituting a Nash equilibrium, is shown by the point of intersection between two straight lines. Such a Nash equilibrium reflects different levels of social welfare in the two countries which correspond to points on the elliptical social indifference curves. ${ }^{12}$ Solid and dashed ellipses are used to distinguish

\footnotetext{
${ }^{12}$ With linear demand and social welfare functions, the reduced form solutions are quadratic in tax rates. This generates elliptical social indifference curves.
} 
the indifference curves for, respectively, the domestic and foreign countries. The inner curves constitute higher levels of social welfare. Note that the Pareto-improving solutions, illustrated by the shaded areas, are all combinations of tax rates that lie inside the two initial social welfare curves.

As shown, for example, in Figure 1a, when the marginal social welfare, in both countries, for private consumption is larger than for public good consumption, a Pareto improvement can be obtained by increasing both indirect tax rates. In keeping with Corollary 1 such a scenario applies when demand for the private good is inelastic in both countries. Again, the intuition is that when demand for the private good is inelastic, tax increases will not generate much erosion of the tax bases in each country, leading to higher overall tax revenues and government expenditures. At the Nash equilibrium, each country has chosen its indirect tax rate optimally in light of a fundamental fiscal tradeoff that it faces. On the one hand, in this inelastic demand case, higher tax rates generate more tax revenues and associated higher employment due to increased public expenditures. On the other hand, higher taxes reduce domestic welfare by depressing domestic demand for the private consumption good. It should be noted that, when consumers have positive marginal propensities to save, the marginal propensities to spend of governments is higher than that of the private sector. Hence, increased tax revenues will promote world demand.

An essential insight is that at the Nash equilibrium, a country's optimal tax rate has been chosen while only considering the consequences of tax changes on domestic and not on world demand. In a scenario where there is global unemployment, higher tax revenues will generate positive international externalities. Higher domestic government expenditures will increase global production by creating a net increase in worldwide public and private sector demand, thereby creating more foreign jobs as well. ${ }^{13}$ In turn, the latter entails increased foreign tax revenues, less social subsidies, and higher foreign private sector consumption. Thus, as compared with the Nash equilibrium, the cooperative solutions entail increased tax revenues which generate international multiplier effects due to increased world demand. If both countries internalize such international externalities there is scope for a cooperative gain. However, since any one country has already optimized its welfare at the Nash solution, while a unilateral increase in its tax rate would result in a net increase in global welfare, that would occur at the expense of a loss in domestic welfare.

The foregoing remarks are readily illustrated in Figure 1a for a case where the two countries are completely symmetric. Relative to the initial Nash tax rates, a (small) unilateral increase in the domestic tax rate decreases the distance between the pair of tax rates and the social optimum of the foreign country, more than it increases the distance to the social optimum of the domestic country. ${ }^{14}$

Figures $1 \mathrm{~b}, \mathrm{c}$ lend themselves to analogous interpretations for scenarios where the underlying social marginal propensities and demand elasticity values are asymmetric in the two countries. Figure 1d illustrates the polar case from that in Figure 1a. Here, since private consumption demand is elastic, Pareto improvement is obtained by decreasing tax rates, in order to generate more government revenues and associated global demand.

The diagrams also illustrate that Theorem 1 is no longer valid if the initial position of the countries is not a Nash equilibrium. For instance in Figure 1a, if the initial position

\footnotetext{
${ }^{13}$ The assumption that there are identical production processes for private and public goods abstracts from issues relating to the relative labor intensity of these two sectors in the two countries.

${ }^{14}$ Geometrically, this welfare change translates into a comparison of the smaller length of the hypothenuse of a triangle, relative to the sum of its two sides.
} 
Figure 1: Simulation of the dependence of Pareto-improving indirect tax rates on social preferences (and demand elasticities).

Diagram (a): demand in both countries is inelastic $\left(E, E^{*}>0\right)$.

Diagram (b): demand in the domestic country is inelastic $(E>0)$ and in the foreign country it is elastic $\left(E^{*}<0\right)$.

Diagram (c): demand in the domestic country is elastic $(E<0)$ and in the foreign country it is inelastic $\left(E^{*}>0\right)$.

Diagram $(\mathrm{d})$ : demand in both countries is elastic $\left(E, E^{*}<0\right)$.

The values of the parameters are as follows: $\lambda=\lambda^{*}=w=w^{*}=10, a=a^{*}=6, b=b^{*}=2$, $T=T^{*}=0.2, N=N^{*}=10, m_{0}=m_{0}^{*}=4, m_{0}^{u}=m_{0}^{u *}=3, s=s^{*}=2, \alpha=1, \theta_{3}=\theta_{3}^{*}=1$. In diagram (a): $\theta_{1}=\theta_{1}^{*}=3, \theta_{2}=\theta_{2}^{*}=2$. In diagram (b): $\theta_{1}=3, \theta_{1}^{*}=2, \theta_{2}=2, \theta_{2}^{*}=3$. In diagram (c): $\theta_{1}=2, \theta_{1}^{*}=3, \theta_{2}=3, \theta_{2}^{*}=2$. In diagram $(\mathrm{d}): \theta_{1}=\theta_{1}^{*}=2, \theta_{2}=\theta_{2}^{*}=3$. 
would be at the other point of intersection of the Nash equilibrium indifference curves, then a Pareto improvement would be obtained by decreasing, instead of increasing, both indirect tax rates.

\section{$5 \quad$ Flexible Wages}

The basic framework of Section 2 serves as a point of departure, but the wages $w, w^{*}$ are now regarded as endogeneous. Under the assumptions of constant returns to scale and zero profits, it is still the case that $\lambda=w$ and $\lambda^{*}=w^{*}$. Hence, in order to accommodate flexible wages within the present framework, marginal productivities (which are equal to the wages) have to be endogenous. This can be justified, for instance, by assuming 'efficiency wages', so that lower wages entail lower productivities. It will moreover be assumed that the marginal productivities in both countries, and hence the wages, are equal. This assumption replaces equation (10), which has to be cancelled because there is no unemployment $(\ell=N$ and $\left.\ell^{*}=N^{*}\right)$. In fact, this set-up may also be interpreted as exhibiting underemployment, but fixed wages and productivity per time unit; $w$ and $\lambda$ are then interpreted as total wage and production per worker.

Inequalities (5)-(8) are meaningless in this framework. They are replaced by the following conditions, which reflect the consumers' positive marginal propensities to save (cf. (6)):

$$
x_{Y}<\frac{1}{1+t} \text { and } x_{Y^{*}}^{*}<\frac{1}{1+t^{*}} .
$$

Equation (11) now reduces to:

$$
\begin{aligned}
g & =N(t x+w T) \\
g^{*} & =N^{*}\left(t^{*} x^{*}+w T^{*}\right)
\end{aligned}
$$

Substituting (33) into (the equivalent of) equation (9) yields:

$$
w=\frac{N(1+t) x+N^{*}\left(1+t^{*}\right) x^{*}}{N(1-T)+N^{*}\left(1-T^{*}\right)}
$$

and by differentiation with respect to the indirect tax $t$ it follows:

$$
\frac{d w}{d t}=\frac{N\left[x+(1+t) x_{q}\right]}{N(1-T)\left[1-(1+t) x_{Y}\right]+N^{*}\left(1-T^{*}\right)\left[1-\left(1+t^{*}\right) x_{Y^{*}}^{*}\right]}
$$

or:

$$
\frac{d w}{d t}=\frac{N x(1+\varepsilon(x))}{N(1-T)\left[1-(1+t) x_{Y}\right]+N^{*}\left(1-T^{*}\right)\left[1-\left(1+t^{*}\right) x_{Y^{*}}^{*}\right]}
$$

where, as before, $\varepsilon(x)$ denotes the price elasticity of $x$. By (32) it follows that the denominator of the expression for $d w / d t$ is positive. So the sign of $d w / d t$ is equal to the sign of $1+\varepsilon(x)$. By similar manipulations as in Section 3 the following expression for $d u / d t$ can be derived:

$$
\frac{d u}{d t}=N\left[A_{1} \frac{d w}{d t}+\left(u_{g}-u_{M}\right) x(1+\varepsilon(x))+\left(u_{X}-u_{g}\right) x_{q}\right]
$$

where

$$
A_{1}:=u_{X} x_{y}(1-T)+u_{g} t x_{y}(1-T)+u_{g} T+u_{M}(1-T)\left[1-(1+t) x_{Y}\right]>0 .
$$

Altogether, the following analogon of Proposition 1 in Section 3 holds: 
PROPOSITION 3 Let $\left(\tilde{t}, \tilde{t}^{*}\right)$ be an interior Nash equilibrium. Then

(i) If $u_{g}>u_{M}$, then $d w / d t($ or $1+\varepsilon(x))$ and $u_{X}-u_{g}$ have the same sign (positive, negative, or zero).

(ii) If $u_{g^{*}}^{*}>u_{M^{*}}^{*}$, then $d w^{*} / d t^{*}\left(\right.$ or $\left.1+\varepsilon\left(x^{*}\right)\right)$ and $u_{X^{*}}^{*}-u_{g^{*}}^{*}$ have the same sign (positive, negative, or zero).

Here, all derivatives are evaluated at the Nash equilibrium $\left(\tilde{t}, \tilde{t}^{*}\right)$.

Also, one derives straightforwardly that

$$
\frac{d u}{d t^{*}}=N A_{1} \frac{d w}{d t^{*}} .
$$

Accordingly, by Proposition 3, the sign of $d u / d t^{*}$ is equal to the sign of $u_{X^{*}}^{*}-u_{g^{*}}^{*}$, under the appropriate conditions on marginal social welfare for government expenditure and endof-period money holdings. Consequently, Proposition 2 and Theorem 1 also hold true in this framework with flexible wages. The intuition for these results is that in this framework with flexible wages and productivities, these endogenous variables play the roles of the employment levels $\ell$ and $\ell^{*}$ in Section 3. Nevertheless, while the qualitative findings of both the fixed and the flexible wage version of our model are similar, it is apparent from an expression as (24) compared with (36), that the quantitative optimal tax changes depend on the functioning of labor markets.

\section{Conclusion}

The findings of the current research have suggested a wider configuration of Pareto-improving, cooperative tax changes than that indicated in other research, notably that of Mintz and Tulkens (1986). Other of the cited earlier contributions have a more specific focus on tax harmonization, which is a more restricted form of tax coordination. In particular, the proposed analysis has demonstrated that cooperative solutions are possible for a full spectrum of combinations of tax changes in the two countries. Such policies include not only unidirectional increases or decreases, but also asymmetric directional changes in each country. These results are shown to be critically dependent on marginal preferences for private and public good consumption and end-of-period money balances, along with demand elasticity values relative to unit elasticity. Thus, the findings of this paper underscore the complexity of international tax coordination, while suggesting that simple harmonization rules may have little validity in the presence of major economic asymmetries between countries.

A priority for further research is undoubtedly to further investigate how the core of Pareto-improving cooperative indirect tax changes depend on other variables and parameters of the model. Notably, these include the direct tax rates, government unemployment payments, nominal wage rates, and relative preferences for private and public goods, as well as savings. This analysis should highlight the role of asymmetries between the countries, for these and other variables. Other suggestions for continued research include more fundamental modifications of the basic model. In particular, the analysis could be modified to incorporate alternative modeling assumptions - including those related to the specialization of production between regions, non-traded goods, labor migration in response to income tax differentials, and the joint provision of certain public goods supplies between regions. Relaxing the assumption of balanced budgets would permit an investigation of the interrelation 
between tax harmonization, fiscal, monetary and exchange rate policies. A welfare investigation of the dynamics of international tax reform also appears as a challenging avenue for continued work. The consideration of market structures other than perfect competition could introduce second-best considerations, which might entail modifications of certain of the basic propositions in this paper. Nonetheless, generalization of this model's basic framework would encounter analytical obstacles, so that there are clear trade-offs relative to the specificity of results. Finally, empirical estimation of the welfare gains and other economic implications of alternative international tax harmonization schemes, when countries have different fiscal structures, remains a research priority. ${ }^{15}$

\section{Bibliography}

Atkinson, Anthony B., and Joseph E. Stiglitz (1980): Lectures on Public Economics. New York: McGraw-Hill.

Cnossen, Sybren (ed.) (1985): Tax Coordination in the European Community. Deventer (NL): Kluwer.

Cnossen, Sijbren, and Carl S. Shoup (1985): "Coordination of Value-added Taxes," in: Cnossen (1985), 59-84.

Crombrugghe, Alain, and Henry Tulkens (1989): "On Pareto Improving Commodity Tax Changes Under Fiscal Competition," CORE Discussion Paper No. 8705, Catholic University of Louvain.

Keen, Michael (1987): "Welfare Effects of Commodity Tax Harmonisation," Journal of Public Economics, 33, 107-114.

Keen, Michael (1989): "Pareto-improving Indirect Tax Harmonisation," European Economic Review.

Lahiri, Sajal, and Pascalis Raimondos-Moller (1998): "Public Good Provision and the Welfare Effects of Indirect Tax Harmonisation," Journal of Public Economics, 67, 253-267.

Lockwood, Ben (1997): "Can International Commodity Tax Harmonisation Be ParetoImproving When Governments Supply Public Goods?" Journal of International Economics, 43, 387-408.

Lopez-Garcia, Miguel-Angel (1998): "On Welfare and Revenue Effects of Indirect Tax Harmonization," Economics Letters, 60, 185-193.

Melvin, James R. (1979): "Short-Run Price Effects of the Corporate Income Tax and Implications for International Trade," American Economic Review, 69, 765-774.

Mintz, Jack and Henry Tulkens (1986): "Commodity Tax Competition Between Member States of a Federation: Equilibrium and Efficiency," Journal of Public Economics, 29, $133-172$.

Owen, Robert F. and Hans Peters (1990): "International Tax Coordination, Economic Integration and Welfare: a Game-Theoretic Approach," University of Maastricht, Report M90-04.

Rose, Manfred (1985): "Optimal Tax Perspective on Tax Coordination," in: Cnossen (1985), 113-138.

\footnotetext{
${ }^{15}$ Melvin (1979) has suggested that differences between corporate taxes in the United States and Canada are among the most important non-tariff barriers to these countries' international trade.
} 
Wildasin, David E. (1988): "Nash Equilibria In models of Fiscal Competition," Journal of Public Economics, 35, 229-240. 